\title{
Preliminary study on return water of water resources allocation in city
}

\author{
X.N. LI ${ }^{1,2, a^{*}}$, X.J. Zhao ${ }^{1,2, b}$ \\ ${ }^{1}$ Guizhou Survey/Design Research Institute for Water Resources and Hydropower, \\ Guiyang,Guizhou province, China \\ ${ }^{2}$ State Key Laboratory of Water Resources and Hydropower Engineering Science, Wuhan \\ University, Wuhan,Hubei province, China \\ alixinan1985@126.com, btzhaoxj@vip.sina.com
}

\section{Keywords: Water resources; Allocation; Urban return water; Preliminary study}

Abstract.Several links of water resources allocation is introduced in city, on the basis of supply analysis, water demand prediction and supply-demand balance analysis, the frame of water resources allocation and the structure of urban return water are put forward, in view of the present research situation, the urban return water mechanism is promoted. The study not only provide theoretical reference to return water problems base on water resources allocation, but also give important guiding significance to the rational development and utilization of water resources in city.

\section{Introduction}

Water is the basic guarantee of human life and production, which is the indispensable important basic resources, strategic economic resources and public resourcesin the social development[1]. With the development of society and economy, human demand for water have been continued to increase, competition and contradictions for water resources increasingly prominent, also in order to solve these problems effectively, the water resources allocation theory is put forward and has been widely used.Water resources allocation is that within the scope of the basin or specific area, based on principle of effectiveness, justice and sustainability, using a variety of engineering or non-engineering measures, in accordance with the laws of the market economy and the rule of the allocation of resources, reasonablycontrolling demand, ensuring the effective supply, maintaining and improving the ecological environment quality, adjusting effectively relationship between water consumption departments and the region[2].City is a gathering place and residential place of human, which is the main research object to water resources allocation, and the city's water resources allocation theory has been applied, Gan analyzed the water resources system from supply, using, consumption and discharge, the water resources allocation of Beijing has been set up, which implement the integrated configuration of water resources [3].Amult-objective, multi-sources and multi- user water resources optimal allocation model has been set up by Li [4] which analyzed the condition of Xinzheng city on lack of water, which established a good evaluation index to effect evaluation analysis, and the result of the allocation provides a theoretical basis for decision-making for the optimized allocation of water resources.However, urban drainage problems have emergedafter water resources allocation in city, the drainage problem has become one of the problems which restrict the development of the city, and the return water (treated or untreated sewage discharge) has become the main factors which is influencingecological environment of the regional and downstream city.Focusing on the problems, the compensation mechanism and compensation measures are studied by $\mathrm{He}$ in view of the water construction project, and some economic measures, management measures and engineering measures are proposed [5].Meanwhile, 
the water quality of return water has been evaluated by Xingin Yellow River irrigation area in Ningxia province [6]. At present, the city water resources allocation under the research of urban return water rarely study work, therefore, this articleresearch on urban return water structure on the basis of water resources allocation framework, and build urban return water mechanism, for which the water resources allocation research provide a theoretical reference.

\section{The basic frame work of urban water resources allocation}

Water resources allocation isto solve the contradiction between water supply and water demand subject process, which isdivided into water supply analysis, water demand prediction and supply-demand balance analysis. The research objective of urban water resources allocation is urban water resources allocation system, which is a composite system coupling with the ecological environment, social economic system andwater resource engineering in water resources deployment activities (refer with: Fig. 1).

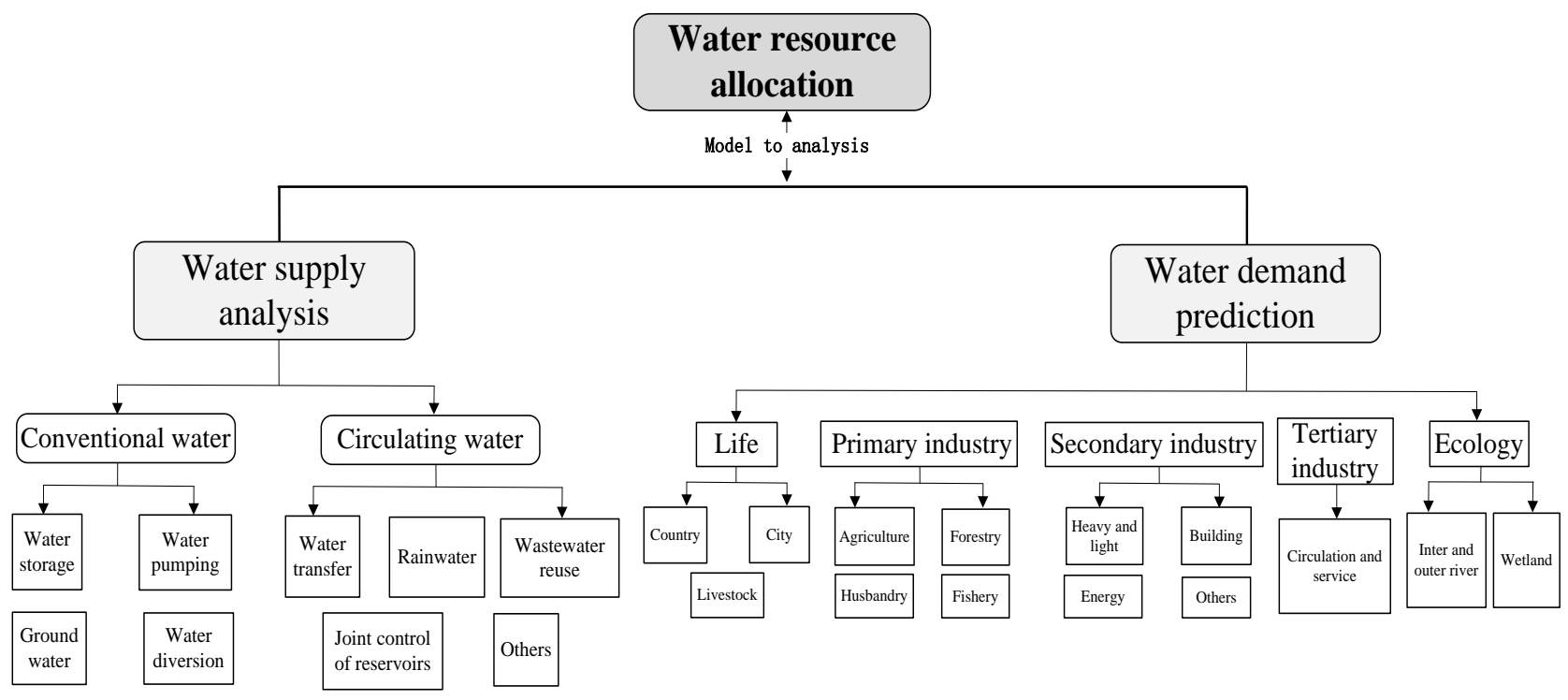

Figure 1. Water resources deployment activities

Water supply analysis. Water supply analysis is the analysis of urban water supply capacity on different levels year, differentassurance rate. According to the water cycle pattern can be divided into urban water supply can be divided into conventional water and circulating water[7]. Conventional water mainly includes water storageengineering, water pumping engineering, water diversion engineering and groundwater engineering, etc.circulating water mainly includes water transfer engineering, rainwater engineering, wastewater reuse engineering and joint control of reservoirs engineering, etc.

Conventional water (refer with: the left in Fig.1): (1) Water storage engineering (reservoir engineering) mainly means reservoir and small reservoir engineering (excluding specially designedregulating reservoir for water diversion engineering and water pumping engineering). (2) Waterdiversionengineeringmainly means artesian water diversion project from the surface river and lakes (excluding from water storage engineering, water diversion engineering of water pumpingengineering). (3) Water pumping engineering mainly means the water is pumped from surface sources such as rivers and lakes water engineering. (4) Groundwater engineering is all theengineering for the development and utilization of water resources under the surface engineering, such as spring water and deep well. 
Circulating water (refer with: the left in Fig.1): (1) Water transfer engineering is also called the water diversion engineering, which is different to conventional water diversion engineering, mainly refers tothe water resources main area or independent basin transferbetween and within the water transfer engineering (water storage, water diversion and water pumping not belong to the engineering). (2) Rainwater engineering refers to a complete set of development and utilizationengineering of urban rain and flood. (3) Wastewater engineering refers to the sewage treatment plant and sewage reuse project engineering, purification water re use engineering and ecological engineering, etc. (4) Joint control of reservoirs is mainly for joint dispatching ofreservoir group in city, which plays a positive role in urban flood control and drainage.

Water demand prediction. Water demand prediction is always the emphasis and difficulty in the city water resources optimal allocation, especially in recent years, the condition of water using is changing widely in China, therefore, predicting the future water demand reasonably, there are of great realistic significance to promote a long-term, stable and rapid economic and social development[8]. At present, the prediction method of water demand based on industry forecast method in China (refer with: the right of Fig.1), mainly divided into life (country, city and livestock), primary industry (agriculture, forestry, husbandry and fishery), secondary industry (heavy and light industry, building, energy and others), tertiary industry (circulation and service) and ecology (wetland, inner river and outer river).

The methods of water demand prediction mainly include the following categories: (1) index analysis (classification quota method), trend analysis (linear/nonlinear regression prediction), time series method and mathematical model calculation method. However, with the development of urbanization the methods are clearly deficient, so some more methods need to be researched.

Water supply-demand balance analysis. Supply-demand balance analys is traditionallyrefers to calculation and analysis of the balance between water supply and water demand in different planning period, namely, the solution process of the contradiction between water supply and water requirement subject.With the increasing knowledge water resources supply- demand balance analysis, the process in knowledge from simple to complex, namely, from the simple configuration, reasonable configuration to optimization configuration process, from the perspective of single area tomacroscopic area, fromsingle objective to multi-objective (social, economic, environmental, ecological and other target).Water resources allocation is multi-level, multi-objective,decision-making complexsystem engineering; however urban return water problemsare ignoredin the process of water resources allocation in city, which is one of the main problems of the city water resources development and regional water security. At present, there is few the studies of urban return water, just a few examples to analyze the return water influence[4,9], and a few studies of return water quality[6,10], the studies of urban return waterhas not yet carried out its mechanism systematically. Above all, under the frame of the urban water resources allocation, establish reasonably mechanism of returnwater is very necessary and urgent.

\section{The structure of return wate $r$ in city}

City return water refers to sewage or liquid wastein the process of the various industries development.City return water have great influence to city and itsdownstream areas, mainly displays in pollution of the city and downstream areas such as environmental pollution, water pollution, biological pollution, which not only affect the development and utilization ofcity water resources, but also a serious threat to urban and regional water security. 
The structure of city return water mainly includes wastewater discharge, irrigation drainage, rain and flood drainage, recycled water discharge, street flushing drainage and others, which form the structure of city return water (refer with: Fig. 2).

Wastewater discharge is mainly refers to sewage and wastewater from the daily life of residents and livestock;recycled water, which is between supply-water and wastewater, is mainly refers to reuse water is that waste-water and rain-water are treated as quality water, can be used to some requirements.Irrigation drainage mainly refers to agricultural return water, inwhich wastewater and waste liquid in the process of agricultural production in crop cultivation, livestock husbandry, and food manufacture.Street flushing drainage is mainly refers to water is discharged by sprinkler, which is used to road maintenance, cleaning, cooling and dust elimination, is one of the major sources of non-point source pollution in city.Rain and flood drainagein city, mainly refers to the return water come from the regional rainfall and flood discharge, also is one of the major sources of non-point source pollution in city.

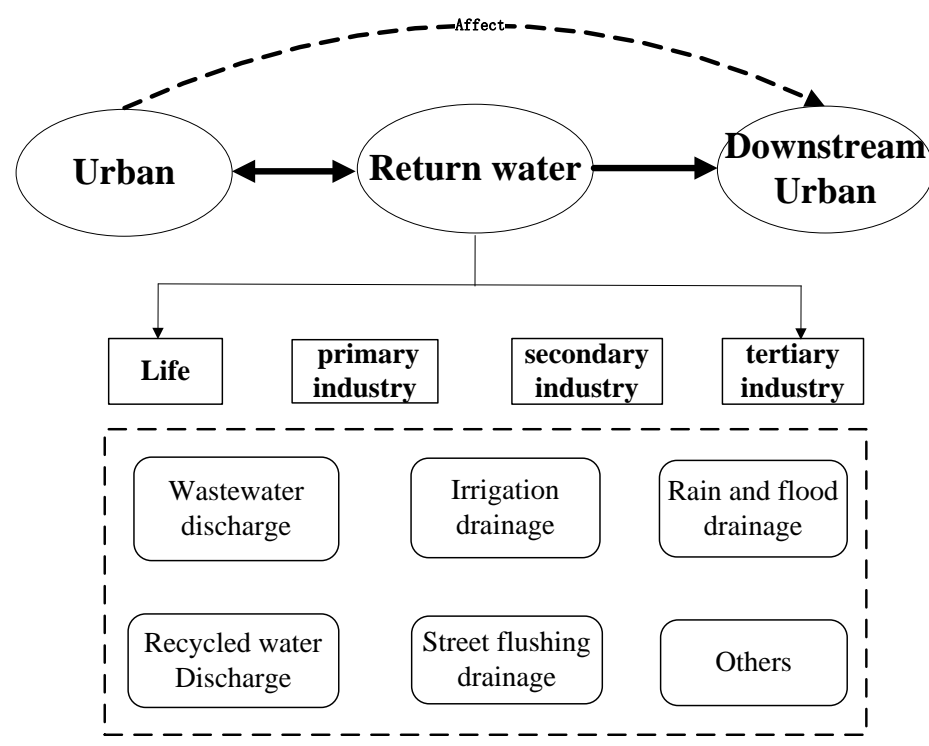

Figure 2. The structure of return water

\section{Return water mechanism research in city}

The return water mechanism is established in city based on the construction of urban water resources allocation mechanism, first of all, the structure of supply-water and demand water should be analyzed based on supply-water analysis and demand water prediction in water resources allocation mechanism in city (refer with:Fig.1); secondly, comparing the supply-water structure and demand water structure, combining with the characteristics of the city, and analyzing the structure of urban return water (refer with: Fig.2); and then, Setting up the urban return water mechanism. Without loss of generality, 5 measures were proposed to build the urban return water mechanism based on urban water resources allocation, and the roles which played in the mechanism were studied in city (refer with: Fig.3).

Water demands control. The total amount control and water-use efficiency control, managing urban water resources based onmarketorientation, and making control to water demands and efficiency for some water users in different conditions, especially restraining some industries that high pollution or low efficiency.

Drainage control. The drainage is limited comprehensive considering the pollutant carrying capacity of the city and its downstream areas, the city water treatment standard and water treatment 
ability should be improved, and strengthen urban drainage control ability, the urban agricultural irrigation and drainage systems should be improved.

Recycled water control. Strengthening the water reuse, restrainingwater discharge, actively promoting energy conservation and emissions reduction, and achieving the efficient utilization of urban water resources.

Storm water and flood control. To establish modern urban rain-flood system, reduce the pollution of the urban rain and flood, unified management and rational utilization of rain-flood, establishgreen rain infrastructure such as biological stranded, roof greening, penetration pavement, rainwater wetland, plant buffers and so on.

Return water control.Taking source control, approach control and end control, which will cut downreturn water discharge from beginning to end. To solve the problem, urban return water must be control the source, and taking effectively measures to reduce the urban return water between and within areas.

The mechanism advantages as follows: (1) The mechanism is beneficial to improve the structure of water in city, playing a positive role in urban water resources allocation, making it more scientific and reasonable. (2) The mechanism can effectively promote the efficient utilization of urban water resources; conform to the urban development needs. (3) The mechanism provides the reference to water conservancy project and municipalengineering, and help to promote modernization.

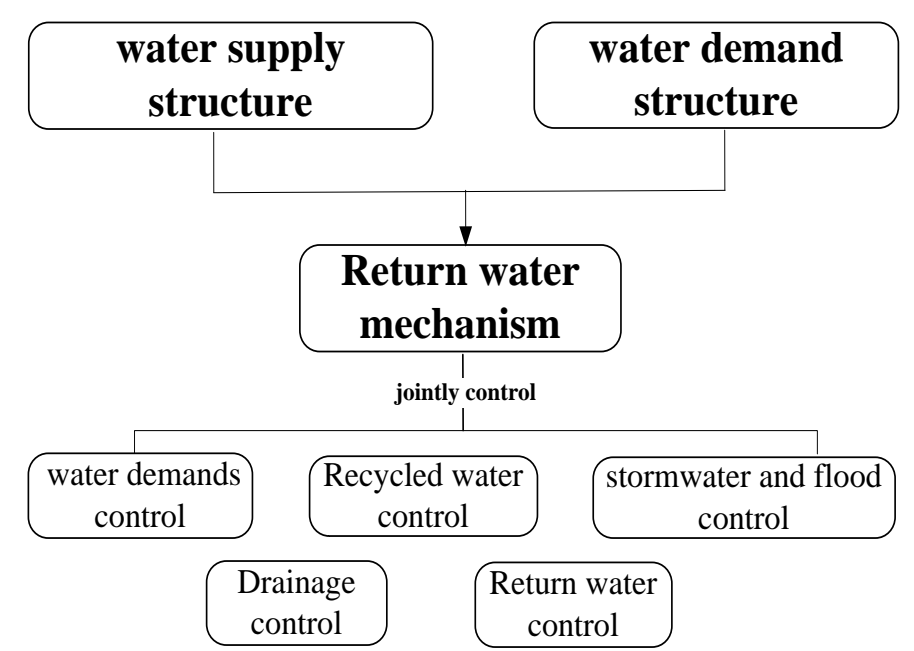

Figure 3. Study on return water mechanis $\mathrm{m}$

\section{Conclusion}

The urban return water mechanism is structured based on the frame of urban water problems in the water resources allocation in the paper. There are many advantages to urban development, which to reduce the environmental pollution in city and improve the water-use efficiency, promote water ecological civilization construction. However, the mechanism still has deficiencies need to further study in the later work, the concrete measures to urban return water mechanism need to be further discussed, and the rational analysis to the frame of the mechanism should be verified by examples. Above all, The study not only provide theoretical reference to return water problems base on water resources allocation, but also give important guiding significance to the rational development and utilization of water resources in city. 


\section{Acknowledge ment}

Thank you for the project (Research and Application of Key Technologies in QianZhong Water Conservancy Project [2012]6013, and Planning of Technology in Guizhou [2015]3006) supported by Guizhou Science and Technology Project.

\section{References}

[1] Y.J. WANG, X.J. GUAN.Prediction of Water Resource Demands in Xinzheng City. Bulletin of soil and Water Conservation. 2010, 30(6):208-213

[2] H. WANG, J. J. YOU.Advancements and development course of research on water resources deployment. Journal of Hydraulic Engineering.2008, 39(10): 1168-1175.

[3] Z.G.GAN, Y.Z.JIANG. Water resources deployment model for Beijing City. Journal of Hydraulic Engineering . 2008, 39(1):91-96.

[4] X. N.LI, X. J.GUAN. Study on optimal allocation of water resources on the scene of shortage of Xinzheng city. Water Resources and Power. 2010, 28(5):14-17.

[5] X.C.HE, S.B. CUI. Studies on compensation system and measure for abstraction and return waters of construction project. China water resource. 2009, (2):27-30.

[6] J.J.XING, X.B.QI. The Application of Grey Clustering Method for Evaluating the Subsiding Water Quality from Cropland in the Irrigation Area of the Yellow River. Journal of Irrigation and Drainage.2011, 30(1):72-75.

[7] Z.M.SHI, X.N.LI. Analysis of Influence of Urban Water Recycle on Urban Water Supply Quantity.Water Saving Irrigation.2012,(6):49-42.

[8] H.F. WANG, J.HE. Research on water demand forecast method and problems. Water Resources Development Research. 2009, 19-24.

[9] F.L.KONG, D.J.YU.Impact analysis of returned water of water supply engineering in middle cities of Jilin Province. China Water Resources. 2011, 17: 51-52.

[10] Y.L. ZHANG, H.E.LI. Research of recession flow on the loess slope and its nitrogen pollution. Journal of Xi'an University of Architecture \& Technology (Natural Science Edition). 2007, 39(1):66-72. 